\title{
New Fuzzy Dynamic Evaluation For ERP Benefits
}

\author{
Berlin Wu, (Email: berlin@math.nccu.edu.tw), National Chengchi University, Taiwan \\ Liping Kao, (Email: Liping.kao@mail.chihlee.edu.tw), Chihlee Institute of Business and Technology, Taiwan
}

\begin{abstract}
The purpose of this paper is to present a new dynamic approach in the ERP benefits evaluation. We use essential financial indicators to compute the impact of sample entities which performed ERP implementation before March 31, 2003 in China and Taiwan. Different from the traditional evaluation methods, our approach is based on the fuzzy statistical analysis and fuzzy rule based decision support system. From the field study we observe that both in China and Taiwan, the ERP implementation makes a negative impact at the first few years. It is surprising that most enterprises don't reach the positive performance as they expected. However, the nuance lies in the fact that with a the long-term, Taiwan shows a significant progress, while in China after ERP implementation it still keeps negatively related performance.
\end{abstract}

\section{INTRODUCTION}

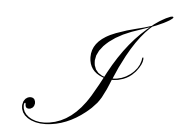

n recent years, Enterprise Resource Planning (ERP) systems have been used by many companies due to expectations of lower operating costs, short cycle times, and higher customer satisfaction. For instance, in Taiwan there more than 90 percent of large-scale retailers have introduced or planned to implement ERP. In China many enterprises, such as Legend, Ze Jing Electricity, and Haier, have invested huge capital in ERP. ERP advocates claim that the positive benefits of ERP will contribute to firm's increased financial performance and enhanced competitive situation.

But after many enterprises noticed advantages and conducted ERP, they found that they got little even negative benefit from it. Moreover, huge capital charges, difficult implementation, long-term efforts, and slow effects may diminish the benefits of ERP implementation. It has been estimated that about $95 \%$ of the enterprises are not successful in helping the improvement of company finance after applied the ERP [26]. For example, more than half of Taiwan enterprises think inducing ERP does not attain optimistic benefit as they expected. Some experts even describe the dilemma of ERP as: "One-third Successes, One-third Fails and One-third Reforms" or "Investing ERP is just like throwing billions of dollars into the ocean".

The other reason of failure of applying ERP comes from the time lag problem as well as the business cycle. In fact, ERP implementations may have lengthy project windows of 3 to 5 years contributing to higher costs. It is argued that a longer time horizon after implementation analysis is preferred [15, 23, 33].

On the other hand, in the face of the important business projects, there are many companies perform the ERP are unable to examine its profitable improvement. The main reason is that it is not easy to set up an appropriate evaluation on ERP performance. Since accurately computing the ERP performance is still problematic, there are many features such as economic conditions changing, new political policy performing and transportation will influence the outcome.

However, there are some approaches in detecting or testing procedures for ERP performance evaluation. Among them t-test or event study method for evaluating the performance of ERP are the mostly frequency used [20, $25,28,33$. These procedures, although easy to implement, have several disadvantages. The main reason for the decimal cost/benefit comparison comes from that measuring ERP benefits are not immediately evident, but 
$\underline{4}$

implementation costs can be readily identified ex post [20]. Moreover, the absence of an explicit statistical model for the structure changes makes it difficult to investigate statistical properties of the models and to make forecasts.

In this research we propose a new integrated testing procedure for ERP performance evaluation where evaluation contains a single financial factor effect and a single company's performance evaluation. Fuzzy rule base about ERP impact of time and impact of company size are suggested for the testing hypothesis of ERP impact. Finally an empirical study about ERP impact on China and Taiwan is illustrated.

\section{ERP BENEFITS}

\section{The Impact Of ERP}

The ERP is used to substitute traditional separate systems with an integrated suite of new business model, resulting in a compact flow of information through the enterprise. ERP provides the same functionalities of previous individual systems while allowing access to enterprise-wide information by employees throughout the entire company on a controlled basis. The major features of ERP software is the integrated ability among modules, data storing/retrieving processes, management and analysis functionalities [14, 22].

Currently, most ERP packages (i.e., SAP, Oracle etc) are structured into different modules, including: accounting, human resources, manufacturing, and logistics. Each module is business process-specific, accesses a core/shared database, and can be considered a single application from both a user interface and software structure point of view. This structure enables users to develop module-specific competencies and vendors to swiftly modify software structure with new release updates.

It is reported from a consulting survey results of Fortune 500 companies that the benefits of ERP for cost reductions and revenue improvements including: inventory and personnel reduction, productivity and order management improvement, improved information, improved processes, and improved customer responsiveness. Some ERP benefits are directly observable and easily measured. For example, control investments were able to decrease inventory by $50 \%$ and increase sales per employee by approximately $50 \%$ due to its ERP implementation. Purina Mills [33] was able to reduce the headcount in its accounting function by $43 \%$ after implementation of ERP. However, some ERP benefits, such as enhanced customer satisfaction, expanded product configurations, and improved competitive positioning are difficult to observe and measure, particularly in the short run.

The costs associated with ERP implementations can be staggering. Implementation of ERP requires a substantial investment of time, money, and internal resources, and is fraught with technical and business risk. A typical ERP installation has a total cost of about $\$ 15$ million, such as training, integration, testing, conversion, and consulting [17] ${ }^{1}$, [29]. The costs of ERP implementation can be as high as $2 \%$ to $3 \%$ of revenues. Installation takes between one and three years (21 months on average). However, once the ERP is online, implementation costs are relatively easy to quantify ex post.

\section{Evaluating ERP Benefits}

ERP is expected to help improving administration and profitability of firms. Meanwhile ERP implementations do add value to a firm has been extensively debated in qualitative discussion or detailed case studies. There are few literatures or case reports about whether the benefits of ERP implementation exceed its costs or risks. The financial burden of implementing ERP can be staggering [7], [32]. While many studies [6], [12], [27], [31] found information technology associated with decreases in worker productivity, other evidence provides encouraging results of a productivity payoff.

\footnotetext{
1 There numbers tend to be large because ERP has historically been adopted by large firms with large-scale implementation requirements. However, small and medium-sized enterprises that are increasingly adopting ERP has much lower implementation cost, which will tend to push the average cost downward.
} 
Though many firms' mangers argue that at the beginning stage the impacts such as enhanced customer satisfaction, expanded product configurations and improved competitive ability can not be distinguished in the short run, the potential benefits of ERP systems are enormous. In the long run they optimistically belief that the benefits of ERP implementation will turn out to be positive in the long run.

When people use return on Investment (ROI) or earning per share (EPS) to evaluate ERP performance, usually they will get negative returns. For instance, Stedman reports 63 companies with ERP implementation. When asked to balance the quantifiable ERP benefits derived from cost savings and revenue gains against implementation costs, the difference yielded a mean loss of $\$ 1.5$ million per company [30].

Barua, Kriebel and Mukhopadhysy [3] tested a new process-oriented methodology for ex post measurement on Information Technologies impacts. Their results showed significant positive impacts of IT at intermediate level. Brynjolfsson and Hitt [11] used firm-level data on IT spending by 370 large firms. Their results indicated that IT has increased productivity and created substantial value for consumers. Appleton et al. [1] indicates one year after implementing ERP, Par Industries in Moiline,Illinois reduced lead-time, increased on-time delivery performance, decreased work-in-progress inventory, and the time of a shop floor order went from weeks to hours. Brynjolfsson and Hitt [10] find that firms that invested more heavily in business process redesign and devoted more of their information technology resources to increasing customer value (such as, quality, timeliness, convenience) had greater productivity and business performance.

On the other hand, many organizations are not certain that they will realize positive returns. Even worse, many fail to see immediate benefits from moving to ERP or experience adverse effects, such as missed sales and profit targets [24]. For instance, Hershey Foods contributed to $\$ 150$ million in lost sales and analysts worried that Hershey's ERP-related problems could result in a 0.5 percent loss of United States market share [13]. Other literature also reported serious business setbacks and delays due to ERP implementation troubles [18].

The possibility of implementation abandonment is a genuine concern as evidenced by Allied Waste and Waste Management [2]. These adverse results are not unusual as many firms have announced negative results attributed to their ERP implementation. It is known that a time lag is necessary for capturing the performance improvements from information technology [9]. The employees need time to coinvent through their own experimentation and discovery, to find ways for the new system to support their work [8]. Since the enterprises will experience a delamila state after ERP implementation [4], [16] [23], [33], a longer term analysis after ERP implementation is preferred.

Poston et al. [25] investigated the financial impacts of enterprise resource planning implementations. They found no significant improvement for residual income, the ratio of selling and administrative expenses after 3 years ERP system implementation. Further, there was a significant reduction in the ratio of employees to revenues for each of the 3 years examined following the ERP implementation. Hitt et al. [21] analyze firms that have purchased licenses for the Sap R/3 system from which they confirm some important conjectures about the business value of ERP implementations. They compare the productivity and business performance of ERP on firms that adopted ERP with those that did not, and find that ERP adopters are consistently higher than non-adopters in performance across a wide variety of measures. Most of the gains occur during the implementation period, although they illustrated some evidence of a decline in business performance and productivity shortly after completion of the implementation.

Based on the above statements, we will propose a new approach for detecting the influence of ERP on firm performance with dynamic financial data and fuzzy rule base evaluation techniques.

\section{EVALUATING ERP PERFORMANCE}

\section{Previous Methods And Factors Analysis}

Most researches support that when people increase the computer/technology investment, it will positively 
help the firm's administration and benefits, such as lower growth in operating expense, improved cost efficiency and higher return on assets, sales growth and nonproduction labor productivity [34]. In this research we summarize the essential factors with each factor contains 2 features for the ERP evaluation (see [4], [5], [8,], [9], [16], [19], [33]): 1. Analysis of operation (1a) Accounts Receivable Turnover (1b) Inventory turnover; 2. Analysis of profitability (2a) Pretax profit to sales (2b) Gross profit ratio; 3. Analysis of investment return (3a) Return on total assets (3b) Return on common equity;4. Analysis of growth rate: (4a) Sales Growth Rate (4b) Gross Profit Growth Rate, as our financial performance evaluation indicators, the relationship of factors and elements. See Table 1.

Table 1

The Relationship Of Factors And Elements

\begin{tabular}{|c|c|c|}
\hline Factors & Features & Definition \\
\hline \multirow{4}{*}{ Analysis of operation } & \multirow{2}{*}{ account receivable turnover } & Net Revenue \\
\hline & & $\overline{\text { averageaccountsreceivable }}$ \\
\hline & \multirow{2}{*}{ Inventory turnover } & Cost of GoodsSold \\
\hline & & $\overline{\text { average inventories }}$ \\
\hline \multirow{4}{*}{ Analysis of investment return } & \multirow{2}{*}{ return on total assets } & Before Interest and $\operatorname{Tax}(\mathrm{EBIT})$ \\
\hline & & average assets \\
\hline & \multirow{2}{*}{ return on equity } & Before Interest and $\operatorname{Tax}(\mathrm{EBIT})$ \\
\hline & & average equity \\
\hline \multirow{4}{*}{ Analysis of profitability } & \multirow{2}{*}{ pre-tax income to revenues } & Pre - tax income \\
\hline & & revenues \\
\hline & \multirow{2}{*}{ gross profit ratio } & Gross profit \\
\hline & & revenues \\
\hline \multirow{4}{*}{ Analysis of growth rate } & \multirow{2}{*}{ Sales Growth Rate } & Sales of Current period-Sales of Base period \\
\hline & & Sales of Base period \\
\hline & \multirow{2}{*}{ Gross Profit Growth Rate } & Gross Profit of Current period Gross Profit of Base period \\
\hline & & Gross Profit of Base period \\
\hline
\end{tabular}

\section{Designs Of Evaluations}

Since a long term evaluation is necessary for computing the performance improvements with adapting a new system. We will use dynamic evaluation method to analyze the ERP implement. In this study we consider the changes in firm performance from 5years before ERP implementation, and to 1,2,3,4 and 5 years after ERP implementation.

By observing the financial index with $n_{t}$ companies, we evaluate the ERP performance with fuzzy logic rule base. In this research, the degree of financial linguistic fluctuation is set to be \{plunge (very non-efficient) $=$ $[-1,-0.5]$, down $($ non-efficient $)=[-0.5,-0.1]$, unchanged $($ medium $)=[-0.1,0.1]$, up $($ efficient $)=(0.1,0.5)$, and soar (very efficient $)=(0.5,1)$. The fundamental concept in the evaluation design is that in order to measure the steady state behavior after ERP, we use the median filter tool. It is a robust statistics since little changes with certain factors may come from to noise, while outlier of certain factors may infect the evaluation result if we use the mean filtering. The reason we use 1.3 times and 1,1 times of median filter as the threshold values linguistic degree are according to the general experience and human thought. The following procedure demonstrates the evaluation process. 
$\underline{4}$

Algorithm for a single factor's evaluation procedure

Step 1: Let $n_{t}$ be the number of companies at time $\mathrm{t}, x_{i j t}$ : be the $\mathrm{i}^{\text {th }}$ standardize financial feature of $\mathrm{j}^{\text {th }}$ company at the $\mathrm{t}$ year, $\mathrm{i}=1,2, \ldots \mathrm{m}$, be the numbers of features. $\mathrm{J}=1,2, \ldots n_{t} . . \quad$ Calculate $\Delta x_{i j t}=x_{i j t}-x_{i j 0}$, and $R_{i t}=\underset{1 \leq j \leq n_{t}}{\operatorname{median}} \Delta x_{i j t} \mid$.

Step 2: Calculated $l\left(\Delta x_{i j t}\right)$ the $\mathrm{i}^{\text {th }}$ financial linguistic variable of $\mathrm{j}^{\text {th }}$ company at the $t$ year

$$
l\left(\Delta x_{i j t}\right)=\left\{\begin{array}{ccc}
1 & \text { if } & 1.3 R_{i t}<\Delta x_{i j t} \\
0.5 & \text { if } & 1.1 R_{i t}<\Delta x_{i j t} \leq 1.3 R_{i t} \\
0 & \text { if } & -1.1 R_{i t} \leq \Delta x_{i j t} \leq 1.1 R_{i t} \\
-0.5 & \text { if } & -1.3 R_{i t} \leq \Delta x_{i j t}<-1.1 R_{i t} \\
-1 & \text { if } & \Delta x_{i j t}<-1.3 R_{i t}
\end{array}\right.
$$

Step 3: Calculate $\bar{x}_{i t}=\frac{1}{n_{t}} \sum_{j=1}^{n_{t}} l\left(\Delta x_{i j t}\right)$, the financial linguistic value for the average of $n_{t}$ company, $\mathrm{i}=1,2, \ldots \mathrm{m}$.

Step 4: Find $x_{t}=\sum_{i=1}^{m} s_{i} \bar{x}_{i t}$, the weighted ERP performance of a factor, where $s_{i}$ is the weight of the $\mathrm{i}^{\text {th }}$ feature,

$$
\sum s_{i}=1
$$

Step 5: Output the result according to the fuzzy rule base:

If $0.5<x_{t}$, then the ERP performance of the factor is very efficient up to year $\mathrm{t}$.

If $0.1 \leq x_{t}<0.5$, then the ERP performance of the factor is efficient up to year $\mathrm{t}$.

If $-0.1<x_{t} \leq 0.1$, then the ERP performance of the factor is no change up to year $t$.

If $-0.5 \leq x_{t}<-0.1$, then the ERP performance of the factor is non- efficient up to year $\mathrm{t}$.

If $x_{t}<-0.5$, then the ERP performance of the factor is very non-efficient up to year $t$.

\section{Algorithm for macro evaluation procedure}

Step 1: Let $X_{i t}$ be the weighted ERP performance of the $\mathrm{i}^{\text {th }}$ factor, $\mathrm{i}=1,2 \ldots \mathrm{n}$, the number of factors.

Step 2: Find the weighted performance of the macro-ERP.

$$
X_{t}=\sum_{i=1}^{n} F W_{i} X_{i t} \text {, where } F W_{i} \text { is the weight of the } \mathrm{i}^{\text {th }} \text { financial factor, } \sum F W_{i}=1 .
$$

Step 3: Output the result according to the fuzzy rule base: 
$\underline{4}$

If $0.5<X_{t}$, then the macro-ERP performance is very efficient up to year $\mathrm{t}$.

If $0.1 \leq X_{t}<0.5$, then the macro-ERP performance is efficient up to year $\mathrm{t}$.

If $-0.1<X_{t} \leq 0.1$, then the macro-ERP performance is no change up to year t.

If $-0.5 \leq X_{t}<-0.1$, then the macro-ERP performance is non- efficient up to year $t$.

If $X_{t}<-0.5$, then the macro-ERP performance is very non-efficient up to year t.

A test of ERP benefit for a financial factor.

Step 1: Let $c_{i t}$ : be the $\mathrm{i}^{\text {th }}$ standardize financial feature of a company at the $\mathrm{t}$ year, $\mathrm{i}=1,2, \ldots \mathrm{m}$, be the numbers of features.

$$
\text { Calculate } \Delta c_{i t}=c_{i t}-c_{i 0} \text {, and } R_{i t}=\underset{1 \leq j \leq n_{t}}{\operatorname{median}}\left\langle\Delta x_{i j t}\right|
$$

Step 2: Calculated $l\left(\Delta c_{i t}\right)$ the $\mathrm{i}^{\text {th }}$ feature of linguistic value of at the $t$ year

$$
l\left(\Delta c_{i t}\right)=\left\{\begin{array}{ccc}
1 & \text { if } & 1.3 R_{i}<\Delta c_{i t} \\
0.5 & \text { if } & 1.1 R_{i}<\Delta c_{i t} \leq 1.3 R_{i} \\
0 & \text { if } & -1.1 R_{i} \leq \Delta c_{i t} \leq 1.1 R_{i} \\
-0.5 & \text { if } & -1.3 R_{i} \leq \Delta c_{i t}<-1.1 R_{i} \\
-1 & \text { if } & \Delta c_{i t}<-1.3 R_{i}
\end{array}\right.
$$

Step 3: Find $c_{t}=\sum_{i=1}^{n} s_{i} l\left(\Delta c_{i t}\right)$, the weighted ERP performance of a factor,, where $s_{i}$ is the weight of the $\mathrm{i}^{\text {th }}$ feature,

$$
\sum s_{i}=1
$$

Step 4: Output the result according to the fuzzy rule base:

If $0.5<c_{t}$, then the ERP performance of the factor is very efficient at year $\mathrm{t}$.

If $0.1<c_{t}<0.5$, then the ERP performance the factor is efficient at year $\mathrm{t}$.

If $-0.1<c_{t} \leq 0.1$, then the ERP performance the factor is no change at year $t$.

If $-0.5<c_{t} \leq-0.1$, then the ERP performance the factor is non- efficient at year $\mathrm{t}$.

If $c_{t}<-0.5$, then the ERP performance the factor is very non-efficient at year $\mathrm{t}$.

\section{Fuzzy Weight Decision For ERP factors}

In the evaluation process, people used to treating each factor with the equal weight. That is, we assume that the factors have the same contribution to the universe domain. However, in order to get a more accurate evaluation, we had better use different weight, according to their contributions to the object, for different factor. Since then, the macro-performance evaluation will reflect the real world situation. To investigate the fuzzy weight of each factor, we may use the fuzzy set theory and sampling survey technique. Especially, using fuzzy memberships and multiple values assignment, we can get an appropriate fuzzy weight for the object. Hence, let's give a brief definition about fuzzy weight. 
$\underline{4}$

\section{Definition: Fuzzy Weight (Data With Multiple Values)}

Let $U$ be a finite set (a discussion domain), $L=\left\{L_{1}, L_{2}, \cdots, L_{k}\right\}$ be a set of k-linguistic factors on $U$, and $\left\{F S_{i}=\frac{m_{i 1}}{L_{1}}+\frac{m_{i 2}}{L_{2}}+\ldots+\frac{m_{i k}}{L_{k}}, i=1,2, \ldots, n\right\}$ be a sequence of random fuzzy sample on $U, m_{i j}\left(\sum_{j=1}^{k} m_{i j}=1\right)$ is the membership with respect to $L_{j}$. Then, the fuzzy weight was defined as

$$
F W=\frac{\frac{1}{n} \sum_{i=1}^{n} m_{i 1}}{L_{1}}+\frac{\frac{1}{n} \sum_{i=1}^{n} m_{i 2}}{L_{i 2}}+\ldots+\frac{\frac{1}{n} \sum_{i=1}^{n} m_{i k}}{L_{k}}
$$

Example: Let the universe set $\mathrm{U}=\{$ factor 1 , factor 2, factor 3, factor 4$\}$. In a sampling survey with 7 experts, we get the following fuzzy sample for 4 factors, see table 2 :

Table 2

Fuzzy Sample Survey

\begin{tabular}{lcccc}
\hline & Factor 1 & Factor 2 & Factor 3 & Factor 4 \\
\hline$F_{1}$ & 0.4 & 0.1 & 0.2 & 0.3 \\
$F_{2}$ & 0.2 & 0.1 & 0.2 & 0.5 \\
$F_{3}$ & 0.3 & 0.2 & 0.3 & 0.2 \\
$F_{4}$ & 0.3 & 0.2 & 0.4 & 0.1 \\
$F_{5}$ & 0.3 & 0.1 & 0.2 & 0.4 \\
$F_{6}$ & 0.2 & 0.2 & 0.4 & 0.2 \\
$F_{7}$ & 0.5 & 0.1 & 0.3 & 0.1 \\
\hline Total & 2.2 & 1 & 2 & 1.8 \\
\hline weight & 0.31 & 0.14 & 0.29 & 0.26 \\
\hline
\end{tabular}

The fuzzy weight for factors of the universe set is $F W=\frac{0.31}{1}+\frac{0.14}{2}+\frac{0.29}{3}+\frac{0.26}{4}$

\section{AN EMPIRICAL STUDY}

The survey sampling is performed both in Taiwan and China by choosing the companies that have publicly disclosed ERP implementation before March, 2003. The data was assessed from the internet and the literatures data base. The general description is demonstrated at table 3 .

Table 3

Sample Demographics

\begin{tabular}{lcc}
\hline & Taiwan & China \\
\hline Securities \& Futures Institute(Financial Intelligence Bank,SFIB) & 196 & -- \\
www.topoint.com.cn \& www.erpworld.net & -- & 2401 \\
Nothing with this research & -94 & -1850
\end{tabular}


$\underline{4}$

Financial materials are not complete

Consult over documents

Other sources

Total sample companies

$-74-528$

$12 \quad 13$

$63 \quad 36$

Table 4 illustrates the time after implementing ERP performed. Since China does not have many companies performed ERP more than after 5 years, we will concentrated our study for the duration time 9 years, i.e. before 5 years and after 4 years' performing the ERP.

\section{ERP And Firm Performance}

This study empirically examines the influence of ERP technology on firm performance. We examine four financial factors; operation, profitability, investment return and growth rate, each factor has two features, to evaluate the ERP performance. A fuzzy rule base system is constructed when we are making a decision rule.

Table 4

The Time After Implementing ERP Performed

\begin{tabular}{lcccc}
\hline & \multicolumn{2}{c}{ Taiwan } & \multicolumn{2}{c}{ China } \\
\cline { 2 - 4 } & Number & Percent & Number & Percent \\
\hline 1 year after implementing ERP & 63 & $100 \%$ & 36 & $100 \%$ \\
2 year after implementing ERP & 59 & $94 \%$ & 29 & $81 \%$ \\
3 year after implementing ERP & 52 & $83 \%$ & 22 & $61 \%$ \\
4 year after implementing ERP & 44 & $70 \%$ & 16 & $44 \%$ \\
Above 5 year after implementing ERP & 30 & $48 \%$ & 10 & $28 \%$ \\
\hline
\end{tabular}

Sample size varies due to the non-availability of post implementation data for all sample firms.

\section{Factor 1: Analysis Of Operation}

Two financial features of operation are Inventory turnover and Accounts Receivable Turnover. The dynamic evaluation is illustrated at Table 5 .

It can be seen that in China, the dynamic performance of the feature Inventory turnover $\bar{x}_{i t}$ is not efficient $\left(\bar{x}_{i 1}=-0.138, \bar{x}_{i 2}=-0.111, \bar{x}_{i 3}=-0.171, \bar{x}_{i 4}=-0.133\right)$. While the dynamic performance of Accounts Receivable Turnover is efficient after two years' non-efficiency $\left(\bar{x}_{i 1}=-0.431 \quad \bar{x}_{i 2}=-0.259\right)$. The result of operation performance, ERP is not efficient during the first two years. Then the performance moves from negative to positive, while the change is not so steep, the following years its measure is not significant change with the financial performance.

Table 5

Dynamic Performance Of Operation After ERP Implementation

\begin{tabular}{|c|c|c|c|c|c|c|}
\hline Operation performance & & $\mathrm{T}=1$ & $\mathrm{~T}=2$ & $\mathrm{~T}=3$ & $\mathrm{~T}=4$ & $\mathrm{~T}=5$ \\
\hline \multirow{4}{*}{ Accounts Receivable Turnover } & China $\left(\bar{x}_{i t}\right)$ & -0.138 & -0.111 & -0.171 & -0.133 & \\
\hline & Taiwan $\left(\bar{x}_{i t}\right)$ & -0.089 & -0.063 & -0.03 & 0.134 & 0.207 \\
\hline & China $\left(\bar{x}_{i t}\right)$ & -0.431 & -0.259 & 0.333 & 0.250 & \\
\hline & Taiwan $\left(\bar{x}_{i t}\right)$ & -0.273 & -0.264 & -0.33 & 0.175 & 0.339 \\
\hline \multirow[t]{2}{*}{ Factor 1:Operation } & $\operatorname{China}\left(x_{t}\right)$ & -0.285 & -0.185 & 0.081 & 0.058 & \\
\hline & Taiwan $\left(x_{t}\right)$ & -0.181 & -0.164 & -0.18 & 0.156 & 0.273 \\
\hline
\end{tabular}




\section{$\underline{4}$}

$1: \bar{x}_{i t}=\frac{1}{n_{t}} \sum_{j=1}^{n_{t}} l\left(\Delta x_{i j t}\right)$, the financial linguistic value for the average of $n_{t}$ companies, $\mathrm{i}=1,2, \ldots \mathrm{m}$.

2: $x_{t}=\sum_{i=1}^{m} s_{i} \bar{x}_{i t}$, the weighted ERP performance of a factor, where $s_{i}$ is the weight of the $\mathrm{i}^{\text {th }}$ feature.

As for the case in Taiwan, the performance of the feature Inventory turnover $\bar{x}_{i t}$ at the three years is no change $\left(\bar{x}_{i 1}=-0.089, \bar{x}_{i 2}=-0.063, \bar{x}_{i 3}=-0.03\right)$. Then the performance becomes efficient year after year. While of Accounts Receivable Turnover becomes efficient after two years' non-efficient. In general, the operation performance is not efficient during the first three years. Then the performance moves from negative to positive and at the fifth year the performance becomes efficient.

\section{Factor 2. Analysis Of Profitability}

Two financial features of profitability are Gross profit ratio and Pretax profit to sales. The dynamic evaluation is illustrated at Table 6.

\section{Table 6}

Profitability after ERP implementation

\begin{tabular}{ccccccc}
\hline Profitability performance & & $\mathbf{T = 1}$ & $\mathbf{T}=\mathbf{2}$ & $\mathbf{T}=\mathbf{3}$ & $\mathbf{T}=\mathbf{4}$ & $\mathbf{T}=\mathbf{5}$ \\
\hline Gross profit ratio & China $\left(\bar{x}_{i t}\right)$ & -0.069 & -0.214 & -0.159 & -0.133 \\
& Taiwan $\left(\bar{x}_{i t}\right)$ & -0.246 & -0.173 & -0.214 & 0.35 & 0.339 \\
Pretax profit to sales & China $\left(\bar{x}_{i t}\right)$ & -0.093 & -0.135 & -0.100 & 0.000 \\
& Taiwan $\left(\bar{x}_{i t}\right)$ & -0.097 & -0.132 & -0.265 & -0.281 & -0.276 \\
\hline Factor 2: Profitability & China $\left(x_{t}\right)$ & -0.081 & -0.175 & -0.130 & -0.067 & \\
& Taiwan $\left(x_{t}\right)$ & -0.172 & -0.153 & -0.24 & 0.035 & 0.032 \\
\hline
\end{tabular}

\footnotetext{
$1: \bar{x}_{i t}=\frac{1}{n_{t}} \sum_{j=1}^{n_{t}} l\left(\Delta x_{i j t}\right)$, the financial linguistic value for the average of $n_{t}$ company, $\mathrm{i}=1,2, \ldots \mathrm{m}$.

2: $x_{t}=\sum_{i=1}^{m} s_{i} \bar{x}_{i t}$, the weighted ERP performance of a factor, where $s_{i}$ is the weight of the $\mathrm{i}^{\text {th }}$ feature.
}

It can be seen that in China, after first year of ERP implementation, the performance of the feature Gross profit ratio $\bar{x}_{i t}$ is no change, while it becomes worse after the succeeding years, the ERP performance is non-efficient. While the dynamic performance of Pretax profit to sales is no change after two years' non-efficient. The result of profitability performance of ERP is no change.

As for the case in Taiwan, the performance of the feature Gross profit ratio sales at the first three years is non-efficient. Then the performance turns out efficient $\left(\bar{x}_{i 4}=0.35, \bar{x}_{i 5}=0.339\right)$ While the Pretax profit to sales is worse year after year. In general, the profitability performance is non-efficient during the first two years. Then the performance moves from negative to positive, the performance remains unchanged. 

$\underline{4}$

\section{Factor 3. Analysis Of Investment Return}

Two financial features of investment return are Return on common equity and Return on total assets. The dynamic evaluation is illustrated at Table 7.

It can be seen that in China, after ERP implementation, both of the performance of the feature Return on common equity and Return on total assets is non-efficient. The result of investment return after the ERP implementation is non-efficient.

Table 7

Investment Return After ERP Implementation

\begin{tabular}{|c|c|c|c|c|c|c|}
\hline Investment return performance & & $\mathbf{T}=\mathbf{1}$ & $\mathbf{T}=\mathbf{2}$ & $\mathbf{T}=\mathbf{3}$ & $T=4$ & $\mathbf{T}=\mathbf{5}$ \\
\hline \multirow[t]{2}{*}{ Return on common equity } & China $\left(\bar{x}_{i t}\right)$ & -0.367 & -0.429 & -0.409 & -0.267 & \\
\hline & Taiwan $\left(\bar{x}_{i t}\right)$ & -0.281 & -0.281 & -0.382 & -0.439 & -0.379 \\
\hline \multirow[t]{2}{*}{ Return on total assets } & China $\left(\bar{x}_{i t}\right)$ & -0.333 & -0.429 & -0.364 & -0.367 & \\
\hline & Taiwan $\left(\bar{x}_{i t}\right)$ & -0.316 & -0.316 & -0.373 & -0.402 & -0.397 \\
\hline \multirow[t]{2}{*}{ Factor 3: Investment return } & $\operatorname{China}\left(x_{t}\right)$ & -0.350 & -0.429 & -0.387 & -0.317 & \\
\hline & $\operatorname{Taiwan}\left(x_{t}\right)$ & -0.299 & -0.299 & -0.378 & -0.421 & -0.388 \\
\hline
\end{tabular}

\footnotetext{
$1: \bar{x}_{i t}=\frac{1}{n_{t}} \sum_{j=1}^{n_{t}} l\left(\Delta x_{i j t}\right)$, the financial linguistic value for the average of $n_{t}$ company, $\mathrm{i}=1,2, \ldots \mathrm{m}$.

2: $x_{t}=\sum_{i=1}^{m} s_{i} \bar{x}_{i t}$, the weighted ERP performance of a factor, where $s_{i}$ is the weight of the $\mathrm{i}^{\text {th }}$ feature.
}

As for the case in Taiwan, after ERP implementation, both of the performance of the feature Return on common equity and Return on total assets is non-efficient. The result of investment return after the ERP implementation is non-efficient. In general, the investment return exhibits a negative benefit both in China and Taiwan. And there is no inclination to change the situation

\section{Factor 4. Analysis Of Growth Rate}

Two financial features of growth rate are Sales Growth Rate and Gross Profit Growth Rate. The dynamic evaluation is illustrated at Table 8 .

It can be seen that in China, after first year of ERP implementation, the performance of both feature Sales Growth Rate and Gross Profit Growth Rate are negative. The dynamic result of growth rate performance after ERP implementation is from non-efficient to no change.

As for the case in Taiwan, the performance of both feature Sales Growth Rate and Gross Profit Growth Rate are negative. While the Gross Profit Growth Rate is worse year after year. In general, the growth rate performance is non-efficient after ERP implementation. 
Table 8

Growth Rate After ERP Implementation

\begin{tabular}{|c|c|c|c|c|c|c|}
\hline Growth rate performance & & $\mathbf{T}=\mathbf{1}$ & $\mathbf{T}=\mathbf{2}$ & $\mathbf{T}=\mathbf{3}$ & $T=4$ & $\mathbf{T}=5$ \\
\hline Sales Growth Rate & China $\left(\bar{x}_{i t}\right)$ & -0.271 & -0.130 & -0.118 & 0.000 & \\
\hline \multirow{3}{*}{ Gross Profit Growth Rate } & Taiwan $\left(\bar{x}_{i t}\right)$ & -0.194 & -0.241 & -0.261 & -0.224 & -0.231 \\
\hline & China $\left(\bar{x}_{i t}\right)$ & -0.204 & -0.300 & -0.105 & -0.100 & \\
\hline & Taiwan $\left(\bar{x}_{i t}\right)$ & -0.308 & -0.337 & -0.375 & -0.263 & -0.25 \\
\hline \multirow[t]{2}{*}{ Factor4: Growth rate } & $\operatorname{China}\left(x_{t}\right)$ & -0.237 & -0.215 & -0.112 & -0.050 & \\
\hline & Taiwan $\left(x_{t}\right)$ & -0.251 & -0.289 & -0.318 & -0.244 & -0.241 \\
\hline
\end{tabular}

\footnotetext{
$1: \bar{x}_{i t}=\frac{1}{n_{t}} \sum_{j=1}^{n_{t}} l\left(\Delta x_{i j t}\right)$, the financial linguistic value for the average of $n_{t}$ company, $\mathrm{i}=1,2, \ldots \mathrm{m}$.

2: $x_{t}=\sum_{i=1}^{m} s_{i} \bar{x}_{i t}$, the weighted ERP performance of a factor, where $s_{i}$ is the weight of the $\mathrm{i}^{\text {th }}$ feature.
}

\section{The Macro ERP Performance}

In this section we will examine the macro ERP performance via above four financial factors. According to the method of section 3.2, we ask for 7 experts' opinion, and find the fuzzy weight is

$$
F W=\frac{0.31}{1}+\frac{0.14}{2}+\frac{0.29}{3}+\frac{0.26}{4}
$$

The results of macro-ERP performance are illustrated at Table 9.

It is interesting to find that the ERP performance in China exhibits an optimistic progress, from non-efficient to the third year no change. Though the EPR implementation does not meet the expected achievement, we may see from the dynamic trend that as the time goes by it may get the positive benefits.

The same situation can be found in Taiwan, the macro-ERP performance is no change.

Table 9

The Results Of Macro-ERP Performance

\begin{tabular}{llccccc}
\hline & & $\mathbf{T = 1}$ & $\mathbf{T = 2}$ & $\mathbf{T = 3}$ & $\mathbf{T = 4}$ & $\mathbf{T}=\mathbf{5}$ \\
\hline \multirow{6}{*}{ China } & Factor 1:Operation & -0.285 & -0.185 & 0.081 & 0.058 \\
& Factor 2: Profitability & -0.081 & -0.175 & -0.130 & -0.067 \\
& Factor 3: Investment return & -0.350 & -0.429 & -0.387 & -0.317 \\
& Factor4: Growth rate & -0.237 & -0.215 & -0.112 & -0.050 \\
& Macro ERP performance & -0.263 & -0.262 & -0.134 & -0.096 & \\
\hline \multirow{6}{*}{ Taiwan } & Factor 1:Operation & -0.181 & -0.164 & -0.18 & 0.156 & 0.273 \\
& Factor 2: Profitability & -0.172 & -0.153 & -0.24 & 0.035 & 0.032 \\
& Factor 3: Investment return & -0.299 & -0.299 & -0.378 & -0.421 & -0.388 \\
& Factor4: Growth rate & -0.251 & -0.289 & -0.318 & -0.244 & -0.241 \\
\hline
\end{tabular}




\begin{tabular}{ccc}
\hline Macro ERP performance & -0.232 & -0.234 \\
$X_{t}=\sum_{i=1}^{n} F W_{i} X_{i t}$, where $F W_{i}$ is the weight of the $\mathrm{i}^{\text {th }}$ financial factor, $\sum F W_{i}=1$.
\end{tabular}

\section{CONCLUSION}

In this research, we propose new dynamic approaches in ERP evaluation for Taiwan and China ERP implementation during 1996 to 2003 . We use four financial factors with each factor has two features, to evaluate the ERP performance. The application of the fuzzy rule base to examine the benefit of ERP implementation is heuristic. From the single feature of evaluation of ERP, we can see that in China only Accounts Receivable Turnover exhibits positive improvement, the others are getting worse. While in Taiwan, the Inventory turnover, Accounts Receivable Turnover and Cross profit ratios getting better as the year goes by.

As for the impact of the four factors evaluation of ERP: ERP performance in China, the ERP performance of operation, the growth rate and the profitability is no change. But the investment return factor becomes worse than after the ERP implementation. While in Taiwan, the best performance is operation, it exhibits a positive trend, from negative measurement to positive. The ERP performances for other factors are no change.

Suggestions to the China side: (1) many enterprises are public; the western economic administration system is not well constructed. Hence they may reform their administration concept, promote the management system before they perform the ERP. (2)ERP emphasis on integrating the manpower, sales and management department into a complete information system, only apply the accounting model of ERP can not reach the expected performance.

Suggestions to the Taiwan side: After ERP implementation, at the first several years it may be non-efficient or no change, but in the long run (about four years) it is going better. As for the other financial factors, though ERP implementation makes no change during the short run, we believe, in long run it will getting better say after 4 years.

In the sampling survey, owing to the business privacy, many companies as well as the software firms would not like to supply the complete information, this will make the examination work more difficult. Moreover if we can add some non-financial performance indicators, we will get a more satisfied answer.

\section{REFERENCE}

1. $\quad$ E.L. Appleton, How to Survive ERP, Datamation (March 1997).

2. J. Bailey, Trash Haulers are Taking Fancy Software to the Dump, Wall Street Journal, (1999).

A. Barua, C. Kriebel and T. Mukhopadhysy, Information Technology and Business Value: an Analytic and Empirical Investigation, Information Systems Research 6(1) (1995), pp. 409-428.

3. Benchmarking Partners, ERP's Second Wave: Maximizing the Value of ERP-Enabled Processes, Deloitte Consulting Study (1998).

4. D. H. Bender, Financial Impact of Information Processing, Journal of Management Information Systems 3 (2) (1986), pp. 232-238.

A. Bharadwaj, A Resource-Based Perspective on Information Technology Capability and Firm Performance: An Empirical Investigation, MIS Quarterly 24 (March 2000), pp.169-196.

5. H. Brakely, What Makes ERP Effective? Manufacturing Systems 17(3) (1999), pp.120.

6. T. Bresnahan and S. M. Greenstein, The Competitive Crash in Large Scale Computing, in The Mosaic of Economic Growth, Eds., Landau, Taylor, and Wright, Stanford, (CA: Stanford University Press, 1996).

7. E. Brynjolfsson and L.M. Hitt, Computers and Economic Growth Firm Level Evidence, Unpublished Manuscript (MIT Sloan School Cambridge, MA, 1993).

8. E. Brynjolfsson and L.M. Hitt, Beyond Computation: Information Technology, Organizational Transformation and Business Performance, Journal of Economic Perspectives, 14 (4) (2000), pp.23-48.

9. L. M. Hitt and E. Brynjolfsson, Productivity, Business Profitability, and Consumer Surplus: Three Different Measures of Information Technology Value, MIS Quarterly, 20 (2) (1996), pp. 121-142. 
10. E. Brynjolfsson and S. Yang, Information Technology and Productivity a Review of the Literature, $A d v$ Computer 43 (1996), pp.179-214.

11. R. Burritt, Buyer Bewares, Australian CPA 70(8) (2000), pp.48-49.

12. T. Davenport, Serving up ERP Value, COI Mag 1 (8) (1998), pp.26-29.

13. T. Davenport and J. Short, In Search of ERP Paybacks, Computerworld 34 (8) (2000), pp.42

14. Deloitte Consulting, ERP's Second Wave - Maximizing the Value of Enterprise Applications and Processes - A Global Research Report Including Deloitte Consulting’s Perspective: Making ERP Spell ROI (1999).

15. C. Escalle, M. Cotteleer and R. Austin, Enterprise Resource Planning (ERP), Harvard Business School case report no.9-699-020, Boston (1999).

16. K. Girard and M. A. Farmer, Business Soft Firms Sued Over Implementation, www.cnetnews.com. (November 3, 1999).

17. S. Y. Harris and H.L. Katz, Organizational Performance and Information Technology Investment Intensity in the Insurance Industry, Organization Science 2(3) (1991) pp.263-295.

18. D. C. Hayes, J. E. Hunton and J. L. Reck, Market Reaction to ERP Implementation Announcements, Journal of Information Systems 15(1) (2001), pp. 3-18.

19. L. M. Hitt, D. J. Wu, and X. Zhou, Investment in Enterprise Resource Planning: Business Impact and Operation Measures, Journal of Management Information System 19 (1) (2002), pp. 71-98.

20. T. Hoffman, Extending ERP's Reach, Fortune (February 1998), pp.75-151.

21. E. Knorr, Dawn of the Digital Marketplace, Upside (November 1999), p124.

22. M.H. Martin, An ERP Strategy, Fortune 2 (February 1998).

23. R. Poston and S. Grabski, Financial Impacts of Enterprise Resource Planning Implementations, International Journal of Accounting Information Systems 2 (2001), pp. 271-294.

24. S. S. Rao, Enterprise Resource Planning: Business Needs and Technologies, Industrial Management \& Data Systems 100(2) (2000), pp. 81-88.

25. S. S. Roach, Service under Siege-The Restructuring Imperative, Harvard Business Review 69(5) (1991), pp.82-91.

26. J.W. Ross, Surprising Facts about Implementing ERP, IEEE IT Pro (July/August, 1999), pp. 65-68.

27. D. Slater, The Hidden Costs of Enterprise Software, CIO Magazine 11(7) (1998), pp 48-55.

28. C. Stedman, Survey: ERP Cost more than Measurable ROI, Computerworld 33 (14) (1999), p.6.

29. P.A. Strassman, The Squandered Computer; Evaluating The Business Alignment of Information Technologies, The Information Economics Press, New Canaan, CT. (1997).

30. J. Vaughan, Enterprise Applications, Software Magazine 16 (5) (1996), pp. 67-72.

31. L. Wah, Give EPR a Chance, Management Review (May 2000), pp. 20-24.

32. P. Weill, The Relationship between Investment in Information Technology and Firm Performance: A Study of the Valve Manufacturing Sector, Information Systems Research 3(4) (1992), pp.307-333. 


\section{NOTES}

